\title{
INOVAÇÃO E DESENVOLVIMENTO
}

AGRÁRIO: O MACROPROGRAMA DE

AGRICULTURA FAMILIAR DA EMBRAPA E

OS OBJETIVOS CONSTITUCIONAIS

\author{
Mário Cabral \\ Centro Universitário 7 de Setembro (UNI7), Ceará \\ marioandremc@gmail.com

\section{Heloisa Santos} \\ Universidade Presbiteriana Mackenzie, São Paulo \\ heloisa0206@hotmail.com
}

\begin{abstract}
RESUMO: Este trabalho objetiva analisar se a Empresa Brasileira de Pesquisa Agropecuária (Embrapa) tem atuado no fomento à inovação na agricultura familiar, contribuindo para o objetivo constitucional de garantir o desenvolvimento agrário e nacional. A hipótese é de que a Embrapa tem distintas formas de atuar, todas voltadas para o desenvolvimento científico e tecnológico do setor agropecuário brasileiro, mas que também incentiva a inovação na agricultura familiar. O trabalho se deu com base em pesquisa bibliográfica e de dados da Embrapa obtidos, entre outras vias, através da Lei de Acesso à Informação. Os resultados encontrados foram de que: a Embrapa contava, até 2018, com um Macroprograma especificamente voltado à agricultura familiar; esse Macroprograma tinha receitas inferiores aos outros cinco Macroprogramas da Embrapa; o Macroprograma foi descontinuado em 2018. As conclusões apontam que, apesar da discrepância orçamentária, o Macroprograma 6 representava uma importante postura estatal de indução do progresso técnico em atividade fundamental ao País. Nesse sentido, em virtude da descontinuação do Macroprograma, preocupações surgem acerca do papel da Embrapa em fomentar inovações na agricultura familiar, colaborando para o desenvolvimento agrário e a implementação dos objetivos constitucionais.
\end{abstract}

PALAVRAS-CHAVE: Inovação. Desenvolvimento agrário. Agricultura familiar. Embrapa. Objetivos constitucionais.

\section{Innovation and Agrarian Development: Embrapa's Family Farming Macroprogram and the Constitutional Goals}

\begin{abstract}
The present paper aims to analyze whether the Brazilian Agricultural Research Corporation (Embrapa) has been promoting innovation in family farming, contributing to the constitutional objective of guaranteeing agrarian and national development. The hypothesis is that Embrapa has different ways of acting, all aimed at the scientific and technological development of the Brazilian agricultural sector, but also encouraging innovation in family farming. The heretofore mentioned work was based on bibliographic research and Embrapa data obtained, among other sources, through the Law on Access to Information. The results found were as follows: until 2018, Embrapa had a Macroprogram specifically focused on family farming; Such had lower revenues when compared to Embrapa's other five Macrograms; such Macroprogram was discontinued in 2018. The conclusions reached indicate that, despite the budgetary discrepancy, Macroprogram 6 represented an important state stance of inducing technical progress in a fundamental activity in the country. Concerns arise with regards to Embrapa's role in fostering innovations in family farming, contributing to agrarian development and the implementation of constitutional goals.
\end{abstract}


Inovação e desenvolvimento agrário: o macroprograma de agricultura familiar da Embrapa e os objetivos constitucionais

KEYWORDS: Innovation. Agrarian development. Family farming. Embrapa. Constitutional goals.

\section{INTRODUÇÃO}

Sancionada pelo presidente Emílio Garrastazu Médici, a Lei no 5.851, de 7 de dezembro de 1972, instituiu a Empresa Brasileira de Pesquisa Agropecuária (Embrapa) no País, que iniciou suas operações em 26 de abril de 1973 como uma empresa pública, responsável por desenvolver pesquisas e tecnologias relativas à agricultura e pecuária no Brasil ${ }^{1}$.

A Embrapa cumpre fundamental papel na promoção de inovações tecnológicas brasileiras $^{2}$, além de ser um instrumento para a consecução de objetivos constitucionais, como os concernentes ao desenvolvimento nacional e à autonomia tecnológica ${ }^{3}$. Em sua composição, a empresa possuía, até mudanças recentemente operadas que alteraram sua estrutura, seis Macroprogramas, que abrangiam projetos de pesquisa e desenvolvimento (P\&D) com vistas a fomentar competitividade, sustentabilidade e melhorias tecnológicas no setor agropecuário.

O Macroprograma 1 era o responsável por lidar com questões de genômica, abrangendo o desenvolvimento de trabalhos relativos a genética, biologia molecular, melhoramento genético, fisiologia, bioquímica e biologia celular. O Macroprograma 2, por sua vez, envolvia projetos ligados ao estudo do melhoramento genético (isto é, "pré-breeding", "breeding", "teste e validação" e "pós-breeding - produção e mercado") 4 . O Macroprograma 3 cuidava de projetos que necessitavam de ajustes e avanços incrementais, inovações em arranjos simples ${ }^{5}$ e desenvolvi-

1 As finalidades da Embrapa estão dispostas na Lei no 5.851, de 7 de dezembro de 1972: “Art 2º São finalidades da Empresa: I - promover, estimular, coordenar e executar atividades de pesquisa, com o objetivo de produzir conhecimentos e tecnologia para o desenvolvimento agrícola do País; Il - dar apoio técnico e administrativo a órgãos do Poder Executivo, com atribuições de formulação, orientação e coordenação das políticas de ciência e tecnologia no setor agrícola”. BRASIL. Lei no 5.851, de 7 de Dezembro de 1972. Disponível em: http://www.planalto.gov.br/ccivil_03/ leis/1970-1979/L5851.htm. Acesso em: 1 dez. 2018.

2 DE NEGRI, Fernanda. Novos Caminhos para a Inovação no Brasil. Washington: Wilson Center, 2018, p. 79 e 110. Disponível em: http://www.ipea.gov.br/portal/images/stories/PDFs/livros/livros/180615 novos_caminhos_para_a inovacao_no_brasil.pdf. Acesso em: 24 fev. 2019.

3 BERCOVICI, Gilberto. É Fundamental Manter a Embrapa como Empresa Pública. Consultor Jurídico, São Paulo, 1 de maio 2016. Disponível em: https://www.conjur.com.br/2016-mai-01/estado-economia-fundamental-manter-embrapa-empresa-publica. Acesso em: 11 abr. 2018.

4 O pré-breeding é a fase de pré-melhoramento, que envolve "a identificação de genes e características de interesse em germoplasma exótico ou em populações que não foram submetidas a qualquer processo de melhoramento (parentes silvestres e raças locais), e sua posterior incorporação em materiais-elites agronomicamente adaptados". A fase de breeding ou melhoramento tem sido utilizada para "recuperar as características comerciais" do produto, após a obtenção de um híbrido interespecífico. A fase de teste e validação é necessária para que os pesquisadores saibam a capacidade de adaptação e produtividade dos produtos agrícolas objeto de melhoramento genético. Já a fase de pós-breeding ou pós-melhoramento é importante, sobretudo, para "resolver problemas decorrentes do estreitamento da base genética de certas culturas", de modo a permitir a sua produção em maior escala e comercialização. Para maior aprofundamento no tema, vide: FALEIRO, Fábio Gelape; FARIAS NETO, Austeclinio Lopes de; RIBEIRO JÚNIOR, Walter Quadros. Pré-Melhoramento, Melhoramento, e Pós-Melhoramento: Estratégias e Desafios. Disponível em: http://ainfo.cnptia.embrapa.br/digital/bitstream/CPAC-2010/29835/1/faleiro-02.pdf. Acesso em: 25 fev. 2019.

5 A programação de P\&D da Embrapa envolvia a divisão dos projetos de acordo com Arranjos e Portfólios. Os Arranjos consistiam no "agrupamento de projetos que englobavam, preferencialmente, unidades diferentes da Embrapa, que atendiam a desafios de temas específicos, e eram classificados como: convergentes, complementares e sinérgicos". Alguns desafios poderiam ser solucionados mais facilmente, o que fazia com que os arranjos que os envolviam fossem simples. Outros, entretanto, possuíam difícil resolução do ponto de vista da pesquisa e desenvolvimento, o que lhe conferiam um caráter estratégico. Os Portfólios, por sua vez, exerciam apoio gerencial para a gestão de projetos afins, conforme visão temática, como era o caso dos seis Macroprogramas que existiam”. Cf. CRESPI, Tatiane Baseggio; 
mento de protótipos. O Macroprograma 4 era o responsável por oferecer suporte a projetos viabilizados por meio de planos de marketing, produção e comercialização de mudas, publicações e vídeos. Além disso, cuidava de projetos de transferência de tecnologia relacionados a sementes básicas, bem como das questões pertinentes às incubadoras. O Macroprograma 5 viabilizava o desenvolvimento de projetos a partir de gestão do conhecimento, capacitação, melhoria de processos, softwares corporativos e boas práticas de laboratórios. Por fim, havia o Macroprograma 6, que objetivava apoiar o desenvolvimento da agricultura familiar e a sustentabilidade no ambiente rural.

Além dos Macroprogramas, em que eram distribuídos os projetos de $\mathrm{P} \& \mathrm{D}$, a empresa contava com 22 portfólios e 91 arranjos em sua estrutura. Adverte-se que, conforme comunicado emitido pela Embrapa em meados de 2018, a empresa reorganizou todos os seus projetos de forma a que fossem classificados em: "P\&D", "Desenvolvimento e Validação", "Inovação Aberta" e "Apoio à Inovação", excluindo os arranjos e Macroprogramas com direcionamento específico para a realização de atividades. ${ }^{6}$ Todavia, o presente trabalho tem como foco o Macroprograma 6, pertencente à estrutura da empresa até 2018, por sua concentração no fomento da agricultura realizada pelo produtor de pequeno porte, permitindo, inclusive, reflexões sobre a sua efetividade.

Discussões sobre a agricultura familiar ascenderam a partir da década de 1980 no Brasil, em virtude da mobilização e pressão de grupos sociais ${ }^{7}$ por políticas públicas voltadas para esse tipo de atividade. ${ }^{8}$ Tais grupos sociais eram os chamados "povos e comunidades tradicionais" que travaram lutas políticas por direitos de acesso a terra e recursos naturais.

Verifica-se que a agricultura realizada pelo produtor de menor porte era vista no país como "um conjunto de unidades de subsistência que comercializavam excedentes nos mercados locais" $"$. Essa concepção começou a ser modificada somente após 2000, quando houve o desen-

COSTA, Priscila Resende da; PORTO, Geciane Silveira; PREUSLER, Taísa Scariot. EMBRAPA: Estrutura Organizacional e Gestão de P\&D. In: VI Simpósio Internacional de Gestão de Projetos, Inovação e Sustentabilidade, 2017, São Paulo, Anais eletrônicos. São Paulo: SINGEP, 2017. Disponível em: https://singep.org.br/6singep/resultado/ 454.pdf. Acesso em: 11 fev. 2019.

6 EMPRESA BRASILEIRA DE PESQUISA AGROPECUÁRIA. Novos Projetos Vão Priorizar a Inovação. Embrapa, 16 de abr. 2018. Disponível em: https://www.embrapa.br/en/busca-de-noticias/-/noticia/33422090/novos-projetosvao-priorizar-a-inovacao. Acesso em: 01 abr. 2019.

7 CALEGARE, Marcelo Gustavo Aguilar; HIGUCHI, Maria Inês Gasparetto; BRUNO, Ana Carla dos Santos. Povos e Comunidades Tradicionais: das Áreas Protegidas à Visibilidade Política de Grupos Sociais Portadores de Identidade Étnica e Coletiva. Ambiente \& Sociedade. São Paulo, v. XVII, n 3, jul./set. 2014, p. 115-134. Disponível em: http://www.scielo.br/pdf/asoc/v17n3/v17n3a08.pdf. Acesso em: 19 abr. 2019.

8 WIENKE, Felipe Franz. A Noção de Agricultura Familiar no Direito Brasileiro: Uma Conceituação em Torno de Elementos Socioeconômicos e Culturais. JURIS, Rio Grande, v. 27, n. 1, p. 226. Disponível em: https://periodicos.furg.br/juris/article/viewFile/6966/4611. Acesso em: 26 fev. 2019.

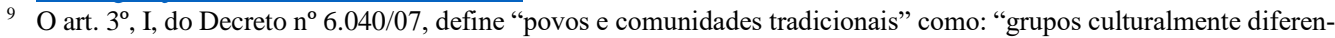
ciados e que se reconhecem como tais, que possuem formas próprias de organização social, que ocupam e usam territórios e recursos naturais como condição para sua reprodução cultural, social, religiosa, ancestral e econômica, utilizando conhecimentos, inovações e práticas gerados e transmitidos pela tradição". BRASIL. Decreto no 6.040, de 7 de Fevereiro de 2007. Disponível em: http://www.planalto.gov.br/ccivil_03/_Ato2007-2010/2007/Decreto/ D6040.htm. Acesso em: 19 abr. 2019.

10 GUANZIROLI, Carlos Enrique; BUAINAIN, Antonio Marcio; SABBATO, Alberto Di. Dez Anos de Evolução da Agricultura Familiar no Brasil: (1996 e 2006). RESR, Piracicaba, v. 50, n. 2, 2012, p. 352. Disponível em: http:// www.scielo.br/pdf/resr/v50n2/v50n2a09. Acesso em: 25 fev. 2019. 
Inovação e desenvolvimento agrário: o macroprograma de agricultura familiar da Embrapa e os objetivos constitucionais

volvimento de um amplo estudo sobre o tema, denominado "Novo Retrato da Agricultura Familiar: O Brasil Redescoberto"11, sob a coordenação de Carlos Enrique Guanziroli e Silvia Elizabeth de C. S. Cardim, realizado a partir da criação de um convênio entre a Organização das Nações Unidas para a Alimentação e a Agricultura (FAO) e o Instituto Nacional de Colonização e Reforma Agrária (INCRA), juntamente com o extinto Ministério do Desenvolvimento Agrário $(\mathrm{MDA})^{12}$. O estudo, ao atualizar a fotografia da agricultura brasileira, revelava uma agricultura familiar com relevância do ponto de vista socioeconômico, fato este que se contrapunha à antiga noção de produção de pequeno porte, apenas para subsistência.

Nesse sentido, o ambiente da extensão rural ${ }^{13}$, cujas experiências são protagonizadas, sobretudo, pelos agricultores familiares, interage com a inovação tendo em vista o enfrentamento de dificuldades comuns no campo, como: "desenvolvimento de territórios, adaptação à mudança climática e o melhoramento da segurança alimentar e qualidade de vida dos habitantes". ${ }^{14}$ Investir em inovação se mostra, assim, fundamental para enfrentar desafios da produção rural de pequenos agricultores.

Considerando que (i) a questão agrária é estratégica para o desenvolvimento desses fatores e, consequentemente, para o desenvolvimento nacional, já que se presta a "uma potencial fonte de geração de empregos, contribuindo para desenvolver as forças produtivas no setor agrícola, induzindo a sua modernização" 15 e encontra respaldo na Constituição Federal de 1988 (CF/ $88)^{16}$; (ii) a Embrapa é uma importante ferramenta institucional para o suporte ao desenvolvimento tecnológico e econômico no campo; e (iii) a agricultura familiar provoca impactos sociais e econômicos desejáveis, o presente trabalho busca indagar acerca dos instrumentos de fomento à inovação da Embrapa dirigidos à agricultura familiar durante o período de 2013 a $2018^{17}$.

Pretende-se com este estudo não somente descrever e entender esses instrumentos de promoção da inovação junto à agricultura familiar por parte da Embrapa, como, igualmente, refletir

${ }^{11}$ GUANZIROLI, Carlos Enrique; CARDIM, Silvia Elisabeth (Coord.). Novo Retrato da Agricultura Familiar: O Brasil Redescoberto. Brasília: 2000. Disponível em: https://www.agencia.cnptia.embrapa.br/recursos/novoretratoID3iTs4E7R59.pdf. Acesso em: 25 fev. 2019.

12 O MDA foi extinto no ano de 2016, através de uma Medida Provisória ( $n^{\circ} 726$ ) que revogou a Lei $n^{\circ} 10.683$, de 28 de maio de 2003. Inicialmente, suas competências haviam sido transferidas para o Ministério do Desenvolvimento Social (MDS). Posteriormente, houve a substituição da pasta do MDA pela Secretaria Especial de Agricultura Familiar e do Desenvolvimento Agrário da Casa Civil da Presidência da República (SEAD) e, com a ascensão de um novo Governo em 2019, o MDS também foi extinto. Como a SEAD teve seu status reduzido pelo novo Governo, parte de suas competências passaram para a nova Secretaria de Agricultura Familiar e Cooperativismo (SAF), vinculada ao Ministério da Agricultura, Pecuária e Abastecimento (MAPA).

${ }^{13}$ O conceito de "extensão rural", enquanto processo, é basicamente: "o ato de estender, levar ou transmitir conhecimentos de sua fonte geradora ao receptor final, o público rural. Todavia, como processo, em um sentido amplo e atualmente mais aceito, extensão rural pode ser entendida como um processo educativo de comunicação de conhecimentos de qualquer natureza, sejam conhecimentos técnicos ou não". PEIXOTO, Marcos. Extensão Rural no Brasil - Uma Abordagem Histórica da Legislação. Consultoria Legislativa do Senado Federal, Textos Para Discussão $n^{\circ}$ 48, Brasília, 2008. Disponível em: https://www12.senado.leg.br/publicacoes/estudos-legislativos/tipos-de-estudos/ textos-para-discussao/td-48-extensao-rural-no-brasil-uma-abordagem-historica-da-legislacao. Acesso em: 19 abr. 2019.

${ }^{14}$ CANAVESI, Flaviane de Carvalho; BIANCHINI, Valter; SILVA, Hur Ben Corrêa da. Inovação na Agricultura Familiar no Contexto da Extensão Rural e da Transição Agroecológica. Disponível em: http://www.ipea.gov.br/ portal/images/stories/PDFs/livros/livros/144174_politica nacional_agroecologia_cap13.pdf. Acesso em: 27 fev. 2019 , p. 387.

15 BERCOVICI, Gilberto. Constituição Econômica e Desenvolvimento: uma Leitura a Partir da Constituição de 1988. São Paulo: Malheiros, 2005, p. 152-153.

${ }^{16}$ Capítulo III do Título VII da CF/88.

${ }^{17} \mathrm{O}$ corte cronológico se deve ao objetivo de limitar o escopo da análise a um quinquênio, contando-se cinco anos para trás a partir do término do governo de Michel Temer e, sobretudo, das alterações no enquadramento de projetos da Embrapa que ocorreu em 2018. 
se tal política, da forma como foi implementada nos últimos anos, presta-se à busca da concretização dos objetivos fundamentais da República, especialmente o desenvolvimento nacional, constante do art. $3^{\circ}$, II, da $\mathrm{CF} / 88^{18}$.

Frente a esse problema, tem-se como hipótese que a proporção dos instrumentos de fomento à inovação no âmbito da pequena agricultura, quando analisada em comparação aos demais Macroprogramas da Embrapa, mostra-se diminuta, acarretando uma tendência a subvalorizar o fomento da agricultura familiar, dificultando, consequentemente, o cumprimento dos objetivos constantes da $\mathrm{CF} / 88(\mathrm{CF} / 88)$.

A presente pesquisa se desenvolverá em quatro passos. Num primeiro momento, será empreendida uma breve análise histórica acerca do papel dos instrumentos estatais de fomento à inovação na agricultura familiar brasileira. Num segundo momento, sob uma perspectiva dogmática, serão mapeados os instrumentos específicos de fomento que existiam até 2018 no âmbito da Embrapa, bem como sua base legal. Numa terceira perspectiva, de eficácia social, o trabalho pretende endereçar uma crítica desses instrumentos de fomento a partir da relevância econômica do Macroprograma 6, referente à agricultura familiar, com relação ao todo que era dispendido pela Embrapa. Por fim, partindo de uma análise prospectiva, as possibilidades de aprimoramento dos instrumentos de amparo às atividades de inovação na pequena agricultura serão discutidas, de modo a verificar, sob a ótica do direito econômico, se o quadro de políticas da Embrapa para a inovação na agricultura familiar se mostra em linha com o objetivo constitucional de superação do subdesenvolvimento ${ }^{19}$.

\section{Os Objetivos Constitucionais, o Direito Econômico e a INOVAÇÃO}

Conforme citado anteriormente, a CF/88 estabelece, em seu art. $3^{\circ}$, que são objetivos fundamentais da República Federativa do Brasil: (i) a construção de uma sociedade livre, justa e solidária; (ii) a garantia do desenvolvimento nacional; (iii) a erradicação da pobreza e da marginalização, bem como a redução das desigualdades sociais e regionais; e (iv) a promoção do bem de todos, sem preconceitos de origem, raça, sexo, cor, idade e quaisquer outras formas de discriminação. Gilberto Bercovici esclarece que a $\mathrm{CF} / 88$ pode ser definida como uma "Constituição Dirigente", no sentido de que seus princípios identificam o regime constitucional vigente e, de igual modo, definem e delimitam a identidade da lei maior perante os cidadãos e a comunidade internacional. ${ }^{20}$ Dessa forma, há uma vinculação do Estado e da sociedade a tarefas voltadas para a transformação social. ${ }^{21}$

A CF/88 conta com uma Constituição Econômica em seu conteúdo normativo. A Constituição Econômica é caracterizada pela presença do aspecto econômico no texto constitucional. Trata-se da aplicação da Constituição política às relações econômicas. Toda economia concreta

\footnotetext{
18 “Art. $3^{\circ}$ Constituem objetivos fundamentais da República Federativa do Brasil: I - construir uma sociedade livre, justa e solidária; II - garantir o desenvolvimento nacional; III - erradicar a pobreza e a marginalização e reduzir as desigualdades sociais e regionais; IV - promover o bem de todos, sem preconceitos de origem, raça, sexo, cor, idade e quaisquer outras formas de discriminação". BRASIL. Constituição da República Federativa do Brasil de 1988. Disponível em: http://www.planalto.gov.br/ccivil 03/Constituicao/Constituicao.htm. Acesso em: $31 \mathrm{dez} .2018$.

$19 \mathrm{O}$ presente artigo segue a proposição metodológica desenvolvida por Gilberto Bercovici: BERCOVICI, Gilberto. Direito Econômico do Petróleo e dos Recursos Minerais. São Paulo: Quartier Latin, 2011, p. 13.

${ }^{20}$ BERCOVICI, Gilberto. Constituição Econômica e Desenvolvimento: uma Leitura a Partir da Constituição de 1988. São Paulo: Malheiros, 2005, op. cit., p. 36.

${ }^{21}$ CABRAL, Mário André Machado. Subdesenvolvimento e Estado de Exceção: o papel da Constituição Econômica e do Estado no Brasil. Rio de Janeiro: Lumen Juris, 2018, p. 30.
} 
Inovação e desenvolvimento agrário: o macroprograma de agricultura familiar da Embrapa e os objetivos constitucionais

se insere em um contexto político governado por normas - as mais relevantes delas são as de natureza constitucional. Dentro do conjunto normativo que compõe a Constituição, há normas que informam e orientam a organização e o desenvolvimento da economia nacional: quais os objetivos econômicos do Estado e da sociedade, quais os limites da atuação de agentes econômicos, quais as formas de intervenção econômica estatal, quais as políticas econômicas priorizadas etc. A Constituição Econômica é responsável por tornar mais clara a ligação tanto entre a Constituição e a política, como entre a Constituição e as estruturas sociais e econômicas do país. ${ }^{22}$ Para que haja implementação da Constituição Econômica, utiliza-se como instrumento o direito econômico, que, na visão de Fábio Konder Comparato, caracteriza-se por um conjunto de técnicas jurídicas utilizadas pelo Estado de modo a realizar sua política econômica, o que constitui uma disciplina da ação estatal em relação às estruturas econômicas, sempre em observância das normas constitucionais. ${ }^{23}$

Além de atingir as estruturas do sistema econômico, com vistas a obter o seu aperfeiçoamento e a sua transformação, o direito econômico possui uma dupla função em países considerados "periféricos" 24 , como é o caso do Brasil, qual seja: a transformação das estruturas socioeconômicas, a fim de garantir a superação do subdesenvolvimento, o que se mostra em conformidade com o objetivo fundamental da República Federativa do Brasil previsto no art. $3^{\circ}$, II, da $\mathrm{CF} / 88 .^{25}$

A busca pela superação do subdesenvolvimento cabe ao Estado e à sociedade, o que se configura como elemento central para o entendimento do direito econômico no Brasil. Sendo assim, há um "caráter contra-fático" no direito econômico, representado pelo fato de que se cuida de conjunto normativo que não se conforma em receber a ordem socioeconômica posta; pretende alterá-la, transformá-la ou, pelo menos, influenciá-la. ${ }^{26}$

Em síntese, o direito econômico, em linha com a missão de construir o desenvolvimento nacional como objetivo constitucional, deve ter sua racionalidade e sua aplicabilidade voltadas para o fim de superar a condição de subdesenvolvimento. Alterar as estruturas socioeconômicas

${ }^{22}$ BERCOVICI, Gilberto. Constituição Econômica e Desenvolvimento: uma Leitura a Partir da Constituição de 1988. São Paulo: Malheiros, 2005, op. cit., p. 37.

${ }^{23}$ COMPARATO, Fábio Konder. O Indispensável Direito Econômico (1965). In: COMPARATO, Fábio Konder. Ensaios e Pareceres de Direito Empresarial. Rio de Janeiro: Forense, 1978, p. 465 e 471. Ver também: CABRAL, Mário André Machado; MASCARENHAS, Fábio Sampaio. Meio Ambiente, Constituição e Direito Econômico: Argumentos Econômicos versus Proteção Animal. Revista Brasileira de Direito Animal, Salvador, v. 13, n. 03, set./ dez. 2018, p. 77-89. Disponível em: https://portalseer.ufba.br/index.php/RBDA/article/download/28578/16985. Acesso em: 28 abr. 2019, p. 82.

${ }^{24}$ Os países periféricos são aqueles que, inicialmente, comercializavam matérias-primas, com base nas exportações, ao passo em que os países de "centro", comercializavam apenas produtos manufaturados, por possuírem uma estrutura voltada para o processo de industrialização. A esse processo econômico dos países periféricos, dá-se o nome de 'desarrollo hacia afuera" ou "desenvolvimento para fora". Entretanto, após haver a assimilação de técnicas provenientes dos países de centro, com a consequente iniciação da industrialização considerada tardia, a periferia iniciou o processo de "derarrollo hacia dentro" ou "desenvolvimento para dentro", o que também chamado de "substituição de importações". Cf. FURTADO, Celso. Teoria e Política do Desenvolvimento Econômico. 10 ed. São Paulo: Paz e Terra, 2000, p. 152-153. Ver também: CABRAL, Mário André Machado. Subdesenvolvimento e Estado de Exceção: o papel da Constituição Econômica e do Estado no Brasil. Rio de Janeiro: Lumen Juris, 2018, op. cit., p. 9.

25 OCTAVIANI, Alessandro. Recursos Genéticos e Desenvolvimento: Os Desafios Furtadiano e Gramsciano. São Paulo: Saraiva, 2013, p. 70-71.

${ }^{26}$ BERCOVICI, Gilberto; OCTAVIANI, Alessandro. Direito e Subdesenvolvimento. In: OCTAVIANI, Alessandro. Estudos, Pareceres e Votos de Direito Econômico. São Paulo: Singular, 2015, p. 70. Ver também: REICH, Norbert. Markt und Recht: Theorie und Praxis des Wirtschaftsrecht in der Bundesrepublik Deutschland. Neuwied/Darmstadt: Hermann Luchterhand, 1977, p. 64-66. Cf. também: GRAU, Eros Roberto. O Direito Posto e o Direito Pressuposto. 7. ed. São Paulo: Malheiros, 2008, p. 59 e 126-127; CABRAL, Mário André Machado. Subdesenvolvimento e Estado de Exceção: o papel da Constituição Econômica e do Estado no Brasil. Rio de Janeiro: Lumen Juris, 2018, p. 51. 
com a finalidade de garantir a superação dessa condição resulta no denominado "Desafio Furtadiano". Conforme Celso Furtado, o desafio se coloca com a reforma das estruturas que pesarem sobre a sociedade e comprometem sua estabilidade e com a resistência às forças que agem no sentido de enfraquecer o sistema econômico brasileiro, ameaçando a unidade nacional. ${ }^{27}$

É preciso, nesse contexto, remontar à ideia de que a condição de subdesenvolvimento poderia ser superada com a internalização, pelos países periféricos, do progresso técnico, desde que cumulado com uma disseminação de seus efeitos por toda a sociedade. ${ }^{28}$ Tal progresso não consiste simplesmente na obtenção de uma modernização tecnológica. Necessita-se da organização de um sistema nacional de inovação com caráter periférico ${ }^{29}$. Ademais, um sistema nacional de inovação periférico deve englobar, além da internalização dos centros decisórios, um sentido distributivo, uma vez que a disseminação de seus efeitos ao longo da sociedade promove a homogeneização social, ou seja, o estado de bem-estar à população, que vai além da mera uniformização dos padrões de vida ${ }^{30} \mathrm{O}$ progresso técnico só pode ser alcançado através da inovação técnica constante, não apenas com invenções, mas, sobretudo, com aperfeiçoamentos com vistas a melhorar as condições de produção, o que tem potencial de acarretar melhorias sociais e econômicas nos espaços em que esse progresso for inserido. ${ }^{31}$ Nesse sentido, é evidente que entidades públicas voltadas para o apoio a atividades de pesquisa e desenvolvimento tecnológico, como a Embrapa, possuem papel relevante na busca pelo progresso técnico e, consequentemente, na criação de sistemas nacionais de inovação periféricos. Ao amparar as comunidades de agricultores familiares em suas atividades de P\&D, a Embrapa permite, sobretudo, o aprimoramento das técnicas agrícolas, o que faz com que os avanços tecnológicos nesse setor ocorram de forma constante.

\section{A Embrapa e os Macroprogramas}

A Embrapa, vinculada ao Ministério da Agricultura, Pecuária e Abastecimento (MAPA), compõe o chamado "Sistema Nacional de Pesquisa Agropecuária" (SNPA), juntamente com as Organizações Estaduais de Pesquisa Agropecuária (Oepas), com as universidades e institutos de

\footnotetext{
${ }^{27}$ FURTADO, Celso. Brasil: a construção interrompida. 2. ed. Rio de Janeiro: Paz e Terra, 1992, p. 13. Sobre o desafio furtadiano, ver: BERCOVICI, Gilberto. Desigualdades Regionais, Estado e Constituição. São Paulo: Max Limonad, 2003, p. 35-44; BERCOVICI, Gilberto. O Ainda Indispensável Direito Econômico. In: BENEVIDES, Maria Victoria de Mesquita; BERCOVICI, Gilberto; MELO, Claudineu de (Orgs.). Direitos Humanos, Democracia e República: Homenagem a Fábio Konder Comparato. São Paulo: Quartier Latin, 2009, p. 516-519; BERCOVICI, Gilberto. Direito Econômico do Petróleo e dos Recursos Minerais. São Paulo: Quartier Latin, 2011, p. 12-14; OCTAVIANI, Alessandro. Recursos Genéticos e Desenvolvimento: os Desafios Furtadiano e Gramsciano. São Paulo: Saraiva, 2013, p. 168-181; BERCOVICI, Gilberto; OCTAVIANI, Direito e Subdesenvolvimento: o Desafio Furtadiano. In: D’AGUIAR, Rosa Freire. Celso Furtado e a Dimensão Cultural do Desenvolvimento. Rio de Janeiro: Centro Internacional Celso Furtado, 2013, p. 49-67; BERCOVICI, Gilberto; OCTAVIANI, Alessandro. Direito e Subdesenvolvimento, op. cit., p. 65-84; CABRAL, Mário André Machado. Subdesenvolvimento e Estado de Exceção, op. cit., p. 3-4.

${ }^{28}$ OCTAVIANI, Alessandro. Recursos Genéticos e Desenvolvimento: Os Desafios Furtadiano e Gramsciano. São Paulo: Saraiva, 2013, op. cit., p. 142.

${ }^{29}$ Idem, p. 142-143.

${ }^{30}$ CABRAL, Mário André Machado. Subdesenvolvimento e Estado de Exceção: o papel da Constituição Econômica e do Estado no Brasil. Rio de Janeiro: Lumen Juris, 2018, op. cit., p. 13.

${ }^{31}$ LÓPEZ, Inmaculada González. La Protección Jurídica de las Invenciones Menores en Europa: Especial Referencia al Modelo de Utilidad. In: BARBOSA, Denis Borges; CABANELLAS, Guillermo; GALLEGO, Beatriz Conde. (Orgs.). Temas de Derecho Industrial y de La Competencia: Propiedad Intelectual, Innovación y Competencia. Buenos Aires: Ciudad Argentina, 2008, p. 383-384.
} 
Inovação e desenvolvimento agrário: o macroprograma de agricultura familiar da Embrapa e os objetivos constitucionais

pesquisa federais e estaduais e, ainda, com as demais organizações vinculadas à pesquisa sobre essa temática no país, sejam elas pessoas jurídicas de direito público ou privado ${ }^{32}$.

O Instituto Agronômico de Campinas (IAC) ${ }^{33}$ e o Departamento Nacional de Pesquisa Agropecuária (DNPEA) ${ }^{34}$ foram os precursores da Embrapa quanto à pesquisa no setor agrícola brasileiro, tendo sido responsáveis por estimular a criação de alguns institutos de pesquisa agrícola regionais, em busca do fortalecimento da integração nacional. ${ }^{35}$

Dados extraídos do Sistema de Gestão de Recursos Humanos Corporativo (SIRH) da Embrapa em dezembro de 2018 revelam que a empresa contava com um total de 9.429 empregados com cargos efetivos, dos quais 2.403 representam pesquisadores, 2.501 analistas, 1.675 técnicos e 2.850 assistentes. ${ }^{36}$ Para além desses, são incluídos em seus recursos humanos 214 empregados detentores de cargos em comissão ou funções de confiança, o que totalizava 9.643 funcionários. ${ }^{37}$ Além disso, em fevereiro de 2019, a Embrapa anunciou um plano de demissão voluntária denominado "Plano de Desligamento Incentivado" (PDI), que pode contemplar quase um terço de seu quadro de funcionários. A iniciativa parte da ideia de que cerca de $75 \%$ dessas vagas possam ser repostas posteriormente. Todavia, as reposições dependem de aprovação dos candidatos em concurso público, o que demonstra que o quadro comum de funcionários da empresa, além de diminuir consideravelmente, pode não ser reposto de forma integral tão rapidamente. ${ }^{38}$

Em relação à infraestrutura, a empresa possuía, também em dezembro de 2018, 16 escritórios e 43 unidades descentralizadas espalhadas pelo território nacional, o que proporciona maior organização e facilidade de atendimento as suas demandas regionais. ${ }^{39}$

${ }^{32}$ EMBRAPA. Sistema Nacional de Pesquisa Agropecuária. Disponível em: https://www.embrapa.br/snpa. Acesso em: 01 dez. 2018.

33 O IAC foi criado no final do Brasil Império, mais especificamente em 1887, pelo conselheiro e Ministro da Agricultura Antônio da Silva Prado. Entre as décadas de 1960 a 1980, o instituto sofreu grave crise econômica, devido a centralização administrativa, econômica e financeira imposta pelo regime da Ditadura Militar de 1964. Atualmente, apontase um desmonte da instituição, em virtude da falta de recursos humanos e financeiros. RAMOS, Pedro; PIACENTE; Fabrício José. O Instituto Agronômico de Campinas: Sua Criação, Importância e um Pouco de sua História. Revista Brasileira de Inovação, n 15, jul./dez. 2016, p. 365-392. Disponível em: https://periodicos.sbu.unicamp.br/ojs/index.php/rbi/article/view/8649134/15683. Acesso em: 19 abr. 2019.

34 Também conhecido como "Departamento Nacional de Pesquisa e Experimentação", o DNPEA era responsável por coordenar todos os órgãos de pesquisa existentes até o momento da criação da Embrapa. Entretanto, o departamento foi extinto por uma Portaria do Poder Executivo no ano de 1973, o que permitiu que a Embrapa herdasse parte de sua infraestrutura. EMBRAPA. História da Embrapa. Disponível em: https://www.embrapa.br/memoria-embrapa/a-embrapa. Acesso em: 19 abr. 2019.

35 OCTAVIANI, Alessandro; NOHARA, Irene. Estatais. São Paulo: Thomson Reuters Brasil, 2019, p. 217.

${ }^{36}$ EMBRAPA. Quantitativo Físico de Pessoal. Posição: Dezembro/2018. Disponível em: https://www.embrapa.br/documents/10180/40797726/Dezembro+Quantitativo+F\%C3\%ADsico+de+Empregados+-+Cargos+Efetivos+-+Optantes+PCE+2012.pdf/bf9a9fdf-32ca-84ec-7d05-491d24a8a135?version=1.0\&download=true. Acesso em: 19 abr. 2019.

${ }^{37}$ EMBRAPA. Quantitativo de Cargos em Comissão e Função de Confiança. Posição: Dezembro/2018. Disponível em: https://www.embrapa.br/documents/10180/40797726/Dezembro+Quantitativo+F\%C3\%ADsico+de+Empregados++Cargos+em+Comiss\%C3\%A3o+e+Fun\%C3\%A7\%C3\%B5es+de+Confian\%C3\%A7a.pdf/5234ff0a-85f7-ff793f1a-da7caa69ef9a?version=1.0\&download=true. Acesso em: 19 abr. 2019.

38 SOCIEDADE NACIONAL DE AGRICULTURA. Embrapa Anuncia Plano de Demissão Voluntária. Disponível em: https://www.sna.agr.br/embrapa-anuncia-plano-de-demissao-voluntaria/. Acesso em: 09 mar. 2019.

${ }^{38}$ EMBRAPA. Unidades - Embrapa no Brasil. Disponível em: https://www.embrapa.br/embrapa-no-brasil. Acesso em: 03 dez. 2018.

${ }^{39}$ EMBRAPA. Unidades - Embrapa no Brasil. Disponível em: https://www.embrapa.br/embrapa-no-brasil. Acesso em: 03 dez. 2018. 
Já no que tange aos seus recursos financeiros, é possível verificar que a Embrapa teve um orçamento de cerca de R $\$ 3.177 .985 .356$ no ano de $2016^{40}$, tendo sido desembolsado um valor superior quando da aprovação da Lei Orçamentária Anual (LOA) de 2017, qual seja: R\$ 3.324.524.658. No ano seguinte, entretanto, em que pese o Projeto de Lei Orçamentária Anual (PLO) ter previsto a destinação de $\mathrm{R}$ \$ 3.452.501.400 à empresa, fato é que somente $\mathrm{R} \$$ 3.444.052.285 foram ratificados pela LOA, o que corresponde a uma dotação orçamentária inferior para o ano de 2018 do que a esperada por seus gestores. Segundo o Portal da Transparência do Governo Federal, a projeção orçamentária da Embrapa para o ano de 2019 é de cerca de R\$ 3,63 bilhões, dado este que reflete uma estagnação nas finanças da empresa ao longo desses últimos anos. ${ }^{41}$

Todos os projetos de P\&D desempenhados por essa empresa pública fazem parte do Sistema Embrapa de Gestão (SEG), adotado a partir de 2002. O SEG, dentro de sua estrutura, abrangia seis "Macroprogramas", conforme citado anteriormente ${ }^{42}$. O "Macroprograma 1 - Grandes Desafios Nacionais" possuía 35 projetos em execução em 2018, que abordavam pesquisas com caráter estratégico, isto é, representavam temas críticos para o agronegócio no Brasil ${ }^{43}$, de elevada base científica e que exigiam intensa aplicação de recursos. Embora o SEG tenha sido reestruturado e os Macroprogramas extintos, seus projetos inconclusos continuam sendo executados dentro da nova estrutura. O projeto "Soluções em Biotecnologias Reprodutivas para os Novos Sistemas de Produção do Brasil" é um exemplo de atividade iniciada no âmbito do Macroprograma 1 e possui como objetivo principal o desenvolvimento de soluções alternativas para os novos sistemas de produção animal brasileiros no contexto da biotecnologia de reprodução. ${ }^{44}$ Em 2018, o Macroprograma 1 não contava com qualquer registro de inviabilização em sua agenda de projetos.

O "Macroprograma 2 - Competitividade e Sustentabilidade Setorial" contava com 207 projetos de $\mathrm{P} \& \mathrm{D}$ em execução, nas mais diversas regiões e ecossistemas do Brasil. Estes, abordavam pesquisas aplicadas, estratégicas e, eventualmente, básicas ${ }^{45}$, que exigiam a organização de redes e equipes interativas. Seu portfólio contava com projetos como o "Pré-Melhoramento do Algodoeiro para Avanços Genéticos na Cotonicultura Nacional", que tinha por objetivo a exploração, geração e disponibilização de novos genótipos, em busca da obtenção de avanços no

${ }^{40}$ EMBRAPA. Relatório de Gestão Exercício 2016. Disponível em: https://www.embrapa.br/documents/10180/ 1549626/Relat\%C3\%B3rio+de+Gest\%C3\%A3o+Embrapa+-+2016/a32af203-2eb2-7b51-fefc-090c92aa8144.

Acesso em: 02 dez. 2018.

${ }^{41}$ CONTROLADORIA-GERAL DA UNIÃO. Portal da Transparência. Empresa Brasileira de Pesquisa Agropecuária EMBRAPA. Despesas do órgão: Execução Orçamentária e Financeira. Disponível em: http://www.portaltransparencia.gov.br/orgaos/22202?ano=2019. Acesso em: 19 abr. 2019.

42 PENTEADO, Maria Isabel de Oliveira; FONTES, Ruy Rezende; CAMPOS, Antônio de Araújo; EUCLIDES FILHO, Kepler. A Trajetória do Planejamento de Pesquisa na Embrapa. In: Cadernos de Ciência \& Tecnologia, Brasília, v. 31, n. 1, p. 35-60, jan./abr. 2014. Disponível em: https://www.alice.cnptia.embrapa.br/alice/bitstream/doc/986015/1/ Trajetoriadoplanejamentodapesquisa.pdf. Acesso em: 05 jan. 2019.

${ }^{43}$ MENDES, Luis Augusto Lobão; ONO, Mauri Seiji (Orgs.). Conselho Estratégico: Guia da Alta Administração para o Desenvolvimento da Estratégia Corporativa. São Paulo: Saraiva, 2014.

44 Esse projeto de P\&D, liderado por Luiz Francisco Machado Pfeifer, iniciou-se em janeiro de 2015 e tem previsão de término para junho de 2020. Para obter maiores informações, vide: EMBRAPA. Soluções em Biotecnologias Reprodutivas para os Novos Sistemas de Produção do Brasil. Disponível em: https://www.embrapa.br/busca-de-projetos/ -/projeto/208242/solucoes-em-biotecnologias-reprodutivas-para-os-novos-sistemas-de-producao-do-brasil. Acesso em: 05 mar. 2019.

45 As pesquisas básicas são aquelas que visam a exploração de novos conhecimentos. MENDES, Luis Augusto Lobão; ONO, Mauri Seiji (Orgs.). Conselho Estratégico: Guia da Alta Administração para o Desenvolvimento da Estratégia Corporativa. São Paulo: Saraiva, 2014. 
Inovação e desenvolvimento agrário: o macroprograma de agricultura familiar da Embrapa e os objetivos constitucionais

melhoramento genético do algodoeiro. ${ }^{46}$ Somente 3 projetos foram inviabilizados no ano de 2018, devido à falta de repasse de verbas.

O "Macroprograma 3 - Desenvolvimento Tecnológico Incremental do Agronegócio" era o que envolvia a maior quantidade de projetos em andamento. Em sua estrutura, iniciou-se o projeto "Uso de Dispositivos Móveis Inteligentes na Classificação de Solos Brasileiros", que representava apenas um dos projetos desse Macroprograma, num universo de 223. Seu objetivo era permitir que o produtor rural pudesse visualizar a classificação de seu solo em tempo real, a partir da entrada de dados, que ocorre via dispositivos móveis. ${ }^{47}$ Ao longo do ano de 2018, apenas 6 projetos foram inviabilizados dentro desse Macroprograma. Buscava-se, a partir desses projetos, o aperfeiçoamento tecnológico do agronegócio e de atividades correlatas de forma contínua. Ademais, demandas de curto e médio prazo eram atendidas por meio desse Macroprograma, através de arranjos simples e com pouca intensidade de aplicação de recursos.

O "Macroprograma 4 - Transferência de Tecnologia e Comunicação Empresarial" tinha por objetivo promover a integração entre a $\mathrm{P} \& \mathrm{D}$ e o mercado, mediante transferência de tecnologia e comunicação empresarial, contabilizando 98 projetos em execução, sendo 5 o número de inviabilizações em 2018, por falta de verbas. Essa estrutura permitia que a Embrapa se relacionasse mais facilmente com a sociedade e com seu público-alvo, como ocorria no projeto "Transferência de Tecnologias e Marketing para os Sistemas de Produção com Milho em Mato Grosso do Sul", que buscava posicionar as cultivares BRS de milho para a diversificação de culturas em sistemas de produção do Mato Grosso do Sul. Essa diversificação pode trazer benefícios para o solo, a conservação de recursos naturais, o manejo de determinadas plantas, a produtividade de cultivos e a sustentabilidade. ${ }^{48}$

O "Macroprograma 5 - Desenvolvimento Institucional" tinha por objetivo garantir o desenvolvimento, uma maior efetividade organizacional e a utilização plena dos recursos humanos da Embrapa. Sua programação contava com 36 projetos em execução, como o "Governança e Gestão do Arranjo Quarentena", por exemplo, que buscava viabilizar métodos que ajudassem na redução de riscos de entrada, dispersão e impactos econômicos. Ademais, o projeto buscava o desenvolvimento de programas de manejo e contingência de pragas quarentenárias no país. ${ }^{49}$ No ano de 2018, 17 projetos desse Macroprograma tiveram sua execução inviabilizada.

Finalmente, o "Macroprograma 6 - Apoio ao Desenvolvimento da Agricultura Familiar e à Sustentabilidade no Meio Rural", sexto e último, era o responsável por oferecer suporte às iniciativas de desenvolvimento sustentável na agricultura realizada por comunidades tradicionais

${ }^{46}$ Esse projeto de P\&D, liderado por José Jaime Vasconcelos Cavalcanti, iniciou-se em outubro de 2015 e foi concluído em setembro de 2019. Para obter maiores informações, vide: EMBRAPA. Pré-Melhoramento do Algodoeiro para Avanços Genéticos na Cotonicultura Nacional. Disponível em: https://www.embrapa.br/busca-de-projetos/-/projeto/210349/pre-melhoramento-do-algodoeiro-para-avancos-geneticos-na-cotonicultura-nacional. Acesso em: 06 mar. 2019.

${ }^{47}$ Esse projeto de P\&D, liderado por Luis de França Silva Neto, iniciou-se em setembro de 2016 e foi concluído em agosto de 2019. Para obter maiores informações, vide: EMBRAPA. Uso de Dispositivos Móveis Inteligentes na Classificação de Solos Brasileiros. Disponível em: https://www.embrapa.br/busca-de-projetos/-/projeto/212225/usode-dispositivos-moveis-inteligentes-na-classificacao-de-solos-brasileiros. Acesso em: 05 mar. 2019.

48 Esse projeto de P\&D, liderado por Marcio Akira Ito, iniciou-se em janeiro de 2017 e possuía previsão de termino para dezembro de 2019. Para obter maiores informações, vide: EMBRAPA. Transferência de Tecnologias e Marketing para os Sistemas de Produção com Milho em Mato Grosso do Sul. Disponível em: https://www.embrapa.br/buscade-projetos/-/projeto/212321/transferencia-de-tecnologia-e-marketing-para-os-sistemas-de-producao-com-milhoem-mato-grosso-do-sul. Acesso em: 05 mar. 2019.

49 Esse projeto de P\&D, liderado por Elisangela Gomes Fidelis, iniciou-se em agosto de 2017 e tem previsão de término para julho de 2020. Para obter maiores informações, vide: EMBRAPA. Governança e Gestão do Arranjo Quarentena. Disponível em: https://www.embrapa.br/busca-de-projetos/-/projeto/213817/governanca-e-gestao-do-arranjoquarentena. Acesso em: 05 mar. 2019. 
e de pequeno porte. Dessa forma, englobava somente 21 projetos em andamento no ano de 2018 , como o "Alternativas Agroindustriais para o Fortalecimento da Cadeia Produtiva de Citros de Base Familiar no Sul do Brasil", que tinha por objetivo o desenvolvimento, a validação e a divulgação de tecnologias para fortalecer a cadeia produtiva de citros de base familiar, colaborando, dessa forma, para a sustentabilidade socioeconômica ${ }^{50}$ Haviam sido inviabilizados 4 outros projetos no âmbito do Macroprograma 6, dos quais 3 foram financiados por fontes alternativas, por motivos de atraso na liberação dos recursos previstos anteriormente ou falta de repasse.

Nota-se que a Embrapa, com seus Macroprogramas, contribuiu para a construção do sistema nacional de inovação no País. É uma instituição que tem como objeto social desenvolver a ciência e a tecnologia no setor agrícola brasileiro, com vistas a incrementar a produtividade do setor e, desse modo, aumentar sua capacidade de impulsionar o desenvolvimento econômico do País. Como visto, a Embrapa incorporou como parte de sua missão institucional fomentar a agricultura familiar, que, por sua vez, cumpre papel no objetivo de construir o desenvolvimento econômico, tecnológico e social no campo. O modo como a Embrapa, até 2018, fomentava a inovação na agricultura familiar é o objeto da próxima seção.

\section{O Macroprograma de Agricultura Familiar e a Inova- ÇÃO}

O agricultor familiar e o empreendedor familiar rural são definidos pelo art. $3^{\circ}$ da Lei $\mathbf{~ n}^{\mathbf{o}}$ 11.326, de 24 de julho de 2006, como quem pratica atividades no meio rural, devendo, para ser considerado como tal, atender a quatro requisitos: (i) não deter, a qualquer título, propriedade maior do que quatro módulos fiscais ${ }^{51}$; (ii) utilizar predominantemente mão de obra da própria família nas atividades econômicas do seu estabelecimento; (iii) ter percentual mínimo da renda familiar originada de atividades econômicas do seu estabelecimento ou empreendimento; e (iv) dirigir seu estabelecimento ou empreendimento com sua famí$\mathrm{lia}^{52}$.

Conforme definição oficial do Poder Executivo Federal, a agricultura familiar corresponde "à gestão da propriedade compartilhada pela família e à atividade produtiva agropecuária como principal fonte geradora de renda" 53 . Entretanto, essa noção que se tem sobre a agricultura

${ }^{50}$ Esse projeto de P\&D, liderado por Roberto Pedroso de Oliveira, iniciou-se em setembro de 2017 e tem previsão de término para agosto de 2020. Para obter maiores informações, vide: EMBRAPA. Alternativas Agroindustriais para o Fortalecimento da Cadeia Produtiva de Citros de Base Familiar no Sul do Brasil. Disponível em: https:// www.embrapa.br/busca-de-projetos/-/projeto/213773/alternativas-agroindustriais-para-o-fortalecimento-da-cadeiaprodutiva-de-citros-de-base-familiar-no-sul-do-brasil. Acesso em: 05 mar. 2019.

51 "Módulo fiscal é uma unidade de medida, em hectares, cujo valor é fixado pelo INCRA para cada município levandose em conta:

(a) o tipo de exploração predominante no município (hortifrutigranjeira, cultura permanente, cultura temporária, pecuária ou florestal);

(b) a renda obtida no tipo de exploração predominante;

(c) outras explorações existentes no município que, embora não predominantes, sejam expressivas em função da renda ou da área utilizada; e

(d) o conceito de propriedade familiar. A dimensão de um módulo fiscal varia de acordo com o município onde está localizada a propriedade. O valor do módulo fiscal no Brasil varia de 5 a 110 hectares”. EMBRAPA. Módulos Fiscais. Disponível em: https://www.embrapa.br/codigo-florestal/area-de-reserva-legal-arl/modulo-fiscal. Acesso em: 26 mar. 2019.

52 BRASIL. Lei no 11.326, de 24 de Julho de 2006. Disponível em: http://www.planalto.gov.br/ccivil_03/_Ato20042006/2006/Lei/L11326.htm. Acesso em: 02 dez. 2018.

53 BRASIL. Secretaria Especial de Agricultura Familiar e do Desenvolvimento Agrário. O Que é Agricultura Familiar. Disponível em: http://www.mda.gov.br/sitemda/noticias/o-que-\%C3\%A9-agricultura-familiar. Acesso em: $02 \mathrm{dez}$. 2018. 
Inovação e desenvolvimento agrário: o macroprograma de agricultura familiar da Embrapa e os objetivos constitucionais

familiar surgiu apenas a partir dos anos 2000, conforme mencionado no capítulo introdutório. O conceito de produção de pequeno porte apareceu no Brasil em meados de 1950, sob a forma de "campesinato". Este era frequentemente associado a um conteúdo político-ideológico que se contrapunha à ideia de latifúndio ${ }^{54}$. $\mathrm{O}$ campesinato, basicamente, incorporava a diversidade de populações agrárias que não eram consideradas patrimonialistas ou, tampouco, proletárias. ${ }^{55}$

A partir de 1970, “a pequena produção” foi o conceito responsável por substituir o campesinato no país e alegadamente "despolitizar" o tema. Nesse momento, estabeleceu-se como principal diferença o tamanho das produções rurais brasileiras, de modo que o contraste entre a pequena, a média e a grande produções fosse ampliado. O ponto benéfico dessa concepção foi o reconhecimento de todas as categorias sociais no meio rural como produtores. Dessa forma, quaisquer deles era suscetível a atendimento por parte de programas governamentais voltados para a agricultura e pecuária. ${ }^{56}$

Posteriormente, o conceito de "agricultura familiar" foi recepcionado no Brasil, considerando o tipo de mão de obra e de gestão empregado. A agricultura familiar é o atual contraste à chamada "agricultura patronal". ${ }^{57}$ Esse tipo de atividade é de suma importância para o desenvolvimento econômico do País em razão, pelo menos, de quatro perspectivas: (i) mão de obra, (ii) ocupação do solo rural, (iii) abastecimento interno e (iv) relevância econômica.

Primeiro, do ponto de vista da mão de obra, a agricultura familiar concentra $74 \%$ do número de trabalhadores na zona rural brasileira, o que equivale a cerca de 12 milhões de pessoas. ${ }^{58}$ Considerando que, atualmente, há 15 milhões de pessoas ocupadas em atividades agropecuárias no país, ${ }^{59}$ tais informações sugerem a centralidade da agricultura familiar para os níveis de empregabilidade do brasileiro, contribuindo para a função social do solo rural.

Segundo, quanto à ocupação do solo rural, de acordo com o Censo Agropecuário do Instituto Brasileiro de Geografia e Estatística (IBGE), realizado em 2017, embora o número total

${ }^{54}$ Cf. ZENERATTI, Fábio Luiz. Propriedade e Latifúndio: Introdução ao Debate sobre sua Origem e Perpetuação no Brasil. In: Caderno de Geografia, v. 27, n. 50, p. 441-454. Disponível em: http://periodicos.pucminas.br/index.php/ geografia/article/download/p.2318-2962.2017v27n50p441/11756. Acesso em: 02 maio 2019.

55 SCHMITZ, Heribert; MOTA, Dalva Maria da. Agricultura Familiar: Elementos Teóricos e Empíricos. Agrotópica, Ilhéus, v. 19, jan./dez., 2007, p. 21-30. Disponível em: http://www.ceplac.gov.br/paginas/agrotropica/revistas/agrotropica 19 1.pdf\#page=24. Acesso em: 02 maio 2019, p. 24.

56 Idem, ibidem.

57 A agricultura patronal é aquela que ocupa áreas maiores e um número menor de propriedades que a agricultura familiar. Cf. ANJOS, Eliane. Agricultura Familiar e Cooperativismo: Notas Introdutórias para o Debate. Disponível em: https://www.ufrb.edu.br/proext/images/Texto_AF_e cooperativismo_GT2 Eliene.pdf. Acesso em: 02 maio 2019.

${ }^{58}$ EMPRESA BRASILEIRA DE PESQUISA AGROPECUÁRIA. Embrapa em Números. 2017. Disponível em: https://www.embrapa.br/embrapa-em-numeros. Acesso em: 01 dez. 2018.

59 Instituto Brasileiro de Geografia e Estatística. Resultados Preliminares | Brasil. Estabelecimentos e Produtores. Censo Agropecuário, 2017. Disponível em: https://censoagro2017.ibge.gov.br/templates/censo_agro/resultadosagro/ pdf/estabelecimentos.pdf. Acesso em: 20 abr. 2019. 
de estabelecimentos rurais tenha diminuído em relação ao censo anterior ${ }^{60}$, nota-se que ele permanece expressivo, totalizando 5.072.152 estabelecimentos. Desses, cerca de 4,4 milhões ${ }^{61}$ são estabelecimentos de agricultura familiar. ${ }^{62}$

Terceiro, no que concerne ao abastecimento interno, também informações do IBGE apontam que parte expressiva de produtos que compõem a cesta básica brasileira (feijão, arroz, mandioca, café, trigo, leite, carne suína, aves, bovinos, entre outros) é produzida por agricultores familiares. ${ }^{63}$

Finalmente, quarto, acerca da relevância econômica, dados do IBGE de 2006 indicavam que a agricultura familiar era responsável pela base econômica de $90 \%$ dos municípios brasileiros de até 20 mil habitantes e por 35\% do produto interno bruto nacional (PIB). ${ }^{64}$ Em 2018, no Brasil, a produção de pequeno porte teria sido responsável por $38 \%$ da produção agropecuária do País. ${ }^{65}$

A despeito das informações quantitativas produzidas acerca da agricultura familiar no Brasil, como as apresentadas anteriormente, Rodolfo Hoffmann estabelece uma crítica em relação a elas, sendo assente no sentido de que não é necessária a criação de estatísticas para mostrar a importância do exercício dessa atividade no país. ${ }^{66}$ Vê-se, pois, que a agricultura familiar tem relevância estratégica para a consecução dos objetivos de construir um país desenvolvido, sem

${ }^{60}$ O Censo Agropecuário do IBGE de 2006 apontava que havia 5.175.489 estabelecimentos rurais no país, dos quais 4.367.902, ou seja, $84,4 \%$, já eram destinados às atividades relacionadas à agricultura familiar. Isso representava $24,3 \%$ da zona rural brasileira em que há atividades de agricultura. A região Nordeste era a que mais abrigava estabelecimentos da agricultura familiar, num total de $50 \%$. Em seguida, havia a região Sul, que concentrava $19 \%$ dos estabelecimentos voltados para essa forma de agricultura no país. $16 \%$ concentravam-se na região Sudeste, $10 \%$ na região Norte e, os outros 5\%, na região Centro-Oeste. Cf. EMPRESA BRASILEIRA DE PESQUISA AGROPECUÁRIA. Embrapa em Números. 2017. Disponível em: https://www.embrapa.br/embrapa-em-numeros. Acesso em: 01 dez. 2018. Segundo o sítio eletrônico do IBGE, a periodicidade do Censo Agropecuário é quinquenal. Todavia, os levantamentos referentes aos anos de 2010 e 2015 não foram levados a efeito, devido aos cortes no orçamento do governo. Dessa forma, um novo Censo foi realizado somente em 2017, sendo esta a base de comparação em relação ao de 2006. Instituto Brasileiro de Geografia e Estatística. Censo Agropecuário de 2006. Disponível em: http:// www.mma.gov.br/estruturas/PZEE/_arquivos/censo_agropecurio_2006_28.pdf. Acesso em: 30 mar. 2019.

61 JUNIOR, Chico. A Hora e a Vez da Agricultura Familiar. O Globo, Rio de Janeiro, 08 de jan. 2018. Disponível em: https://oglobo.globo.com/opiniao/a-hora-a-vez-da-agricultura-familiar-22259699. Acesso em: 26 mar. 2019.

62 O Censo Agropecuário de 2017 não produziu dados efetivos sobre a agricultura familiar no Brasil. Embora a justificativa dada pelo Governo Federal fosse referente ao custo de realização do Censo, que, caso contasse com menos perguntas, seria menos custoso, o presidente do IBGE, Paulo Rabello de Castro, havia assegurado que o universo da agricultura familiar não seria excluído do Censo. Entretanto, o discurso não foi compatível com a realidade. Diversos pesquisadores brasileiros criticaram a justificativa e alegaram que havia viés estratégico na escolha do que eliminar ou não com relação às perguntas, o que resultava em prejuízo especificamente para as informações relativas à agricultura familiar, que foram, de fato, descartadas desse Censo em 2017. Cf. CÂMARA DOS DEPUTADOS. Presidente do IBGE diz que Censo Agropecuário de 2017 será Completo e Preciso. Rádio Câmara, 18 de abr. 2017. Disponível em: https://www2.camara.leg.br/camaranoticias/radio/materias/RADIOAGENCIA/530107-PRESIDENTE-DOIBGE-DIZ-QUE-CENSO-AGROPECUARIO-2017-SERA-COMPLETO-E-PRECISO.html. Acesso em: 01 maio 2017.

${ }^{63}$ HOFFMANN, Rodolfo. A Agricultura Familiar Produz 70\% dos Alimentos Consumidos no Brasil?. Segurança Alimentar e Nutricional, Campinas, v. 21, n. 1, 2014, p. 417-419. Disponível em: http://coral.ufsm.br/ppgagr/images/ Documentos/AF70.pdf. Acesso em: 30 mar. 2019.

${ }^{64}$ Não foi possível obter dados oficiais mais atualizados.

65 GUIMAR ÃES, Elian. Agricultura Familiar Já Responde por Metade da Produção de Alimentos do País. Jornal do Estado de Minas, Minas Gerais, 07 de maio 2018. Disponível em: https://www.em.com.br/app/noticia/agropecuario/ 2018/05/07/interna_agropecuario,956711/agricultura-familiar-metade-da-producao-de-alimentos-mesa-brasileiros.shtml. Acesso em: 30 de mar. 2019. Não foi possível obter dados oficiais.

${ }^{66}$ HOFFMANN, Rodolfo. A Agricultura Familiar Produz 70\% dos Alimentos Consumidos no Brasil?. In: Segurança Alimentar e Nutricional, Campinas, São Paulo. Disponível em: http://coral.ufsm.br/ppgagr/images/Documentos/ AF70.pdf. Acesso em: 30 mar. 2019, p. 418. 
Inovação e desenvolvimento agrário: o macroprograma de agricultura familiar da Embrapa e os objetivos constitucionais

pobreza ou miséria e com menos desigualdades sociais e regionais. Para que a agricultura familiar continue cumprindo seu papel social e econômico, deve-se refletir sobre as formas de incrementar suas competências.

As atividades econômicas usualmente dão saltos históricos de qualidade quando inovações ocorrem. Isto porque o processo de inovação, além de aumentar os ganhos de capital, tende a reduzir os custos de produção. ${ }^{67}$ Nesse sentido, são introduzidas no processo de acumulação de capital novas técnicas, que reduzem a quantidade de trabalho direto e indireto incorporado em um bem. Quando isso ocorre, tem-se o progresso técnico ${ }^{68}$, que, conforme lembra Alessandro Octaviani, reflete "o conjunto de transformações que tornam possível a persistência do processo de acumulação e, por conseguinte, de reprodução da sociedade capitalista." 69 A inovação, nesse passo, é um instrumento do progresso econômico, justamente por permitir que transformações ocorram com vistas a dar prosseguimento à maior acumulação de capital. Contudo, até que seja desenvolvida e permita a redução da quantidade de trabalho incorporada ao bem, trata-se de empreendimento custoso e arriscado. Por conta disso, por vezes, o setor privado não enfrenta tais custos e riscos, notadamente nas fases iniciais, que são percorridas nas trajetórias de inovação.

Nesse contexto, cabe ao Estado cumprir um papel que dificilmente será exercido pela iniciativa privada, fomentando e promovendo o desenvolvimento científico, a pesquisa, a capacitação científica e tecnológica e a inovação, conforme prescreve o art. 218 da CF/88. A Embrapa é parte desse quadro institucional que tem fundamento constitucional. Trata-se de entidade cujo objeto é a produção de conhecimento com vistas a melhorar as competências da agricultura e da pecuária brasileiras. Ocorre que faz parte do setor agrícola a agricultura familiar, contribuindo para o desenvolvimento do País de modo crucial, como apontado acima. E nesse sentido deve ser incentivada de modo a progredir economicamente.

Assim, pode-se esquematizar que (i) a agricultura familiar é fundamental para o desenvolvimento do país, (ii) a inovação é instrumento para promover saltos de qualidade nas atividades econômicas objeto de políticas de fomento e (iii) a Embrapa é expressão da ação estatal com vistas a conferir suporte ao desenvolvimento da agricultura e da pecuária no Brasil. Disso, decorre que é necessária a ação da Embrapa de modo a fomentar a inovação no âmbito da agricultura familiar.

Em atenção a essa necessidade é que a Embrapa desenvolveu o Macroprograma 6, que era, até 2018, o seu principal instrumento de fomento à inovação na agricultura familiar brasileira. Esse Macroprograma possuía como fonte financiadora predominante o Tesouro Nacional (TN). Durante o período de 2013 a 2018, os valores recebidos pela Embrapa para custeio ${ }^{70}$ dos projetos de $\mathrm{P} \& \mathrm{D}$ realizados dentro desse Macroprograma totalizaram R\$35.104.833,22 para o

${ }^{67}$ SALGADO, Rodrigo Oliveira. Constituição e Desenvolvimento: o mercado interno na Constituição de 1988. Dissertação (Mestrado em Direito Econômico e Financeiro) - Faculdade de Direito da Universidade de São Paulo, São Pulo, 2013, p. 53.

68 BRESSER-PEREIRA, Luiz Carlos. Tendência Declinante da Taxa de Lucro e Progresso Técnico. Revista de Economia Política, v. 6, n. 4, out./dez., 1986, p. 23. Disponível em: http://www.rep.org.br/pdf/24-2.pdf. Acesso em: 30 mar. 2019.

69 OCTAVIANI, Alessandro. Recursos Genéticos e Desenvolvimento: Os Desafios Furtadiano e Gramsciano. São Paulo: Saraiva, 2013, p. 183.

${ }^{70}$ Os valores recebidos para custeio são aqueles utilizados especificamente para arcar com as despesas previstas na execução dos projetos do Macroprograma e que não geram expectativa de retorno financeiro à Embrapa e à sociedade. 
TN e R\$ 11.362.200,62 para outras fontes financiadoras, sejam elas diretas ou indiretas. Enquanto isso, os valores de investimento ${ }^{71}$ atingiram a marca de $\mathrm{R} \$ 2.909 .612,52$ para o TN e R\$ 3.562.886,68 para as demais fontes.

Aduz o Memorando $n^{\circ}$ 5/2018-SPD/GPP, emitido pela Embrapa em $1^{\circ}$ de novembro de 2018, nos autos do Pedido de Informação n ${ }^{\circ} 99937000281201834$, que o custeio das atividades dos projetos realizados no âmbito do Macroprograma 6 abrangia: "material de consumo, obras, passagens, diárias, bolsas, serviços com terceiros etc." Entretanto, esse custeio não abrangia as despesas com pessoal diretamente envolvido na execução de cada um dos projetos do Macroprograma 6, uma vez que eram remunerados via rubrica específica para pagamento de pessoal.

No que concerne aos recursos concedidos aos Macroprogramas em 2017, R\$ 29.212.773,99 foram distribuídos aos seis Macroprogramas. Todavia, informações divulgadas pelo Departamento de Pesquisa e Desenvolvimento da empresa demonstravam que o Macroprograma 6 foi o que recebeu a menor parte dessa verba ${ }^{72}$. Não há informações suficientes para aferir com precisão as razões da destinação menor de recursos. Contudo, algumas hipóteses podem ser apontadas. Pode-se indicar como razão para o Macroprograma 6 ter recebido menos verbas o fato de possuir menos projetos em execução que os demais Macroprogramas. De outro lado, a lógica pode ser a inversa: o Macroprograma teria menos projetos porque a ele foi destinada uma menor fatia do orçamento. Aponta-se também a questão dos tipos de projeto desenvolvidos no âmbito desse Macroprograma. Isto é, se as atividades de pesquisa e desenvolvimento realizadas dentro de sua estrutura envolviam apenas pesquisas básicas, não havia a necessidade de se destinar tanta verba a esse Macroprograma como para aqueles que envolviam pesquisas de caráter aplicado, por exemplo. De qualquer modo, é fato que o Macroprograma 6 tinha menos peso relativo, do ponto de vista dos recursos que lhe eram destinados, em comparação com os outros cinco Macroprogramas. Menos recursos implicam menos capacidade de ação. Essa verificação impõe uma reflexão acerca das prioridades da Embrapa, já que, embora os outros cinco Macroprogramas tivessem relevância, o Macroprograma 6 igualmente cumpria papel fundamental na busca da implementação de objetivos caros à $\mathrm{CF} / 88$, como a garantia do desenvolvimento nacional.

O apoio fornecido pela Embrapa sempre foi fundamental para que o agricultor familiar pudesse adquirir condições de desenvolver técnicas de aprimoramento de sua produção, com vistas a obter maior excedente econômico. ${ }^{73}$ Além disso, as atividades agrícolas passaram a ser orientadas pelas considerações de mercado, que exigem soluções mais complexas. ${ }^{74}$ Esse cenário pode ser facilmente enfrentado pelos agricultores familiares se contarem com o apoio da Embrapa. Cite-se, como exemplo, o projeto "Construção Coletiva de Conhecimentos Agroecológicos em Ambientes de Montanha da Região Serrana Fluminense", no âmbito do Macroprograma 6, que trazia uma maior redução do custo de produção, decorrente de uma menor dependência de insumos externos, da minimização das perdas de produção, da melhoria da qualidade dos

71 Os valores recebidos a título de investimento são aqueles utilizados como aplicação de recursos, isto é, que geram expectativa de retorno financeiro à Embrapa e/ou à sociedade. Como exemplo, tem-se a aquisição de novos equipamentos, que são materiais que podem ser utilizados para outros projetos, além daqueles em execução no momento de sua compra.

72 EMBRAPA. Embrapa em Números. 2017. Disponível em: https://www.embrapa.br/embrapa-em-numeros. Acesso em: 01 dez. 2018.

73 EMPRESA BRASILEIRA DE PESQUISA AGROPECUÁRIA. Agricultura Familiar: Prioridade da Embrapa. Brasília: Embrapa, 2001, 56 p. (Embrapa, Texto para Discussão, 9). Disponível em: https://www.alice.cnptia.embrapa.br/ bitstream/doc/106003/1/seatexto09.pdf. Acesso em: 01 maio 2019.

74 GOEDERT, Wenceslau; CASTRO, Antônio Maria Gomes de; PAEZ, Maria Lúcia D’Ápice. O Sistema Embrapa de Planejamento. In: Revista de Administração, São Paulo, v. 30, no 4, p. 19-33, out./dez. 1995. Disponível em: http:// rausp.usp.br/wp-content/uploads/files/3004019.pdf Acesso em: 02 maio 2019, p. 22. 
Inovação e desenvolvimento agrário: o macroprograma de agricultura familiar da Embrapa e os objetivos constitucionais

produtos e da melhoria da qualidade de vida dos agricultores familiares envolvidos no projeto, por conta da diminuição da insalubridade na realização da atividade. ${ }^{75}$

Reitera-se, por fim, a patente ligação entre o Macroprograma 6 da Embrapa e a busca pelo desenvolvimento nacional, já que suas atividades permitiam o abastecimento e a ampliação do mercado interno e o aumento do poder de compra da massa de assalariados rurais, além de fazer com que a produtividade da terra crescesse. ${ }^{76}$ Por isso, mostra-se preocupante a reorganização que se operou na Embrapa a partir de 2018, eliminando os Macroprogramas em favor de uma classificação que não contempla, de modo específico, a agricultura familiar ${ }^{77}$.

Segundo Gleicy Jardi Bezerra e Madalena Maria Schlindwein, o desenvolvimento econômico não ocorre de maneira simultânea e uniforme em todas as regiões. Entretanto, ao ser iniciado em determinados pontos, é capaz de fortificar áreas mais dinâmicas e que apresentam um potencial maior de crescimento $^{78}$. Bezerra e Schlindwein vão além e, ao tratar do desenvolvimento regional, lembram que esse processo, que pode ser exemplificado pelo sistema produtivo local e pelos ambientes inovadores, é estrutural e possui três pilares essenciais: o progresso da própria região, o progresso da comunidade que a habita e o progresso de cada indivíduo que compõe essa comunidade. Partindo dessa concepção, verifica-se que o Macroprograma 6 da Embrapa, embora proporcionalmente contando com menos recursos que outros Macroprogramas, contribuía para que as regiões, comunidades e indivíduos beneficiados pelo programa se desenvolvessem. Além disso, cada um deles progredia individualmente a partir de sua produção local, o que traduz a real importância do Macroprograma 6 para a garantia do desenvolvimento do País.

\section{CONSIDERAÇÕES FINAIS}

Com a agricultura familiar, preza-se pelo emprego no campo, assegura-se a utilização com função social do solo rural, garante-se o abastecimento interno da população brasileira com alimentos que compõem a cesta básica e se contribui com o desenvolvimento econômico local e nacional. Fomentá-la é fundamental. A atuação do Estado para fomentar a inovação no âmbito da agricultura familiar deve, nesse sentido, passar por métodos que contribuam com a possibilidade de saltos de qualidade e produtividade no campo, proporcionando ganhos econômicos à população diretamente envolvida. Historicamente investimentos em inovação têm essa racionalidade e exercem esse papel de incrementar as possibilidades econômicas dos envolvidos. A Embrapa, enquanto empresa estatal que atua no fomento ao desenvolvimento científico e tecnológico de atividades vinculadas aos setores agrícola e pecuário, deve ter isso em mira. E, em verdade, já o tinha: através de um de seus Macroprogramas, que existiu até 2018, a Embrapa

${ }^{75}$ Esse projeto de P\&D, liderado por Renato Linhares de Assis, iniciou-se em agosto de 2017 e tem previsão de término para julho de 2020. Para obter maiores informações, vide: EMBRAPA. Construção Coletiva de Conhecimentos Agroecológicos em Ambientes de Montanha da Região Serrana Fluminense. Disponível em: https://www.embrapa.br/busca-de-projetos/-/projeto/213660/construcao-coletiva-de-conhecimentos-agroecologicos-em-ambientesde-montanha-da-regiao-serrana-fluminense. Acesso em: 02 maio 2019.

76 ALVES, Eliseu; SOUZA, Geraldo da Silva e; MARRA, Renner. Papel da Embrapa no Desenvolvimento do Agronegócio. Disponível em: https://www.alice.cnptia.embrapa.br/bitstream/doc/970779/1/PapeldaEmbrapanodesenvolvimento.pdf. Acesso em: 02 maio 2019, p. 139.

77 EMPRESA BRASILEIRA DE PESQUISA AGROPECUÁRIA. Novos Projetos Vão Priorizar a Inovação. Embrapa, 16 de abr. 2018. Disponível em: https://www.embrapa.br/en/busca-de-noticias/-/noticia/33422090/novos-projetosvao-priorizar-a-inovacao. Acesso em: 01 abr. 2019.

78 BEZERRA, Gleicy Jardi; SCHLINDWEIN, Madalena Maria. Agricultura Familiar como Geração de Renda e Desenvolvimento Local: uma Análise para Dourados, MS, Brasil. Interações - Revista Internacional de Desenvolvimento Local, Campo Grande, v. 18, jan./mar. 2017, p. 3-15. Disponível em: http://www.scielo.br/pdf/inter/v18n1/15187012-inter-18-01-0003.pdf. Acesso em: 21 abr. 2019. 
implementava políticas de desenvolvimento da agricultura familiar, passando pelo fomento à inovação.

Observou-se, porém, que havia uma discrepância entre os recursos destinados a esse Macroprograma e os recursos endereçados aos demais Macroprogramas. Embora não sejam claras as razões dessa defasagem, o dado objetivo é que os recursos divididos entre os distintos Macroprogramas não eram equilibrados. Com mais equilíbrio orçamentário, a Embrapa poderia fazer mais quanto ao incentivo a inovações na agricultura familiar, contribuindo para atividades que são fundamentais para a construção dos objetivos estabelecidos no texto constitucional de 1988 . Além disso, em razão de reorganização da Embrapa em 2018, os Macroprogramas foram eliminados em prol de uma classificação dos projetos com uma nomenclatura ("P\&D”, "Desenvolvimento e Validação", "Inovação Aberta" e "Apoio à Inovação") que aparentemente desconsidera as particularidades da agricultura familiar ${ }^{79}$. A descontinuação do Macroprograma 6 suscita preocupações.

Apesar de ocupar fatia orçamentária menor frente aos outros Macroprogramas, o Macroprograma 6 cumpria papel relevante no fomento da inovação na agricultura familiar. Através dos seus incentivos, contava-se com postura estatal de amparo e indução do progresso técnico em atividade fundamental ao País, com efeitos sobre o desenvolvimento regional e a melhoria das condições de vida das comunidades e indivíduos. Contar com o Estado, por meio da Embrapa e seus instrumentos jurídico-institucionais de intervenção econômica, para apoiar a agricultura familiar, como era o objeto do Macroprograma 6, significa enxergar a inovação como mecanismo estratégico à consecução de objetivos como o desenvolvimento nacional. Nesse passo, a Embrapa é instrumental ao desenvolvimento agrário e à inovação tecnológica, cumprindo papel que poderia ser ainda mais expressivo - também no fomento à agricultura familiar, o que implica reconhecer sua importância na missão de construir o desenvolvimento nacional, conforme estabelece o art. $3^{\circ}$, da $\mathrm{CF} / 88$.

\section{REFERÊNCIAS}

ALVES, Eliseu; SOUZA, Geraldo da Silva e; MARRA, Renner. Papel da Embrapa no Desenvolvimento do Agronegócio. Disponível em: https://www.alice.cnptia.embrapa.br/bitstream/ doc/970779/1/PapeldaEmbrapanodesenvolvimento.pdf. Acesso em: 02 maio 2019, p. 125-171.

ANJOS, Eliane. Agricultura Familiar e Cooperativismo: Notas Introdutórias para o Debate. Disponível em: https://www.ufrb.edu.br/proext/images/Texto_AF_e_cooperativismo_GT2_Eliene.pdf. Acesso em: 02 maio 2019.

BARBOSA, Denis Borges; CABANELlAS, Guillermo; GALLEGO, Beatriz Conde. (Orgs.). Temas de Derecho Industrial y de La Competencia: Propiedad Intelectual, Innovación y Competencia. Buenos Aires: Ciudad Argentina, 2008.

BERCOVICI, Gilberto. Desigualdades Regionais, Estado e Constituição. São Paulo: Max Limonad, 2003.

BERCOVICI, Gilberto. Constituição Econômica e Desenvolvimento: Uma Leitura a Partir da Constituição de 1988. São Paulo: Malheiros, 2005.

79 EMPRESA BRASILEIRA DE PESQUISA AGROPECUÁRIA. Novos Projetos Vão Priorizar a Inovação. Embrapa, 16 de abr. 2018. Disponível em: https://www.embrapa.br/en/busca-de-noticias/-/noticia/33422090/novos-projetosvao-priorizar-a-inovacao. Acesso em: 01 abr. 2019. 
Inovação e desenvolvimento agrário: o macroprograma de agricultura familiar da Embrapa e os objetivos constitucionais

BERCOVICI, Gilberto. O Ainda Indispensável Direito Econômico. In: BENEVIDES, Maria Victoria de Mesquita; BERCOVICI, Gilberto \& MELO, Claudineu de (orgs.), Direitos Humanos, Democracia e República: Homenagem a Fábio Konder Comparato. São Paulo: Quartier Latin, 2009, p. 503-519.

BERCOVICI, Gilberto. Direito Econômico do Petróleo e dos Recursos Minerais. São Paulo: Quartier Latin, 2011.

BERCOVICI, Gilberto; OCTAVIANI, Alessandro. Direito e Subdesenvolvimento: o Desafio Furtadiano. In: D'AGUIAR, Rosa Freire. Celso Furtado e a Dimensão Cultural do Desenvolvimento. Rio de Janeiro: Centro Internacional Celso Furtado, 2013, p. 49-67.

BERCOVICI, Gilberto; OCTAVIANI, Alessandro. Direito e Subdesenvolvimento. In: OCTAVIANI, Alessandro. Estudos, Pareceres e Votos de Direito Econômico. São Paulo: Singular, 2015, p. 65-84.

BERCOVICI, Gilberto. É Fundamental Manter a Embrapa como Empresa Pública. Consultor Jurídico, 01 maio 2016. Disponível em: https://www.conjur.com.br/2016-mai-01/estado-economia-fundamental-manter-embrapa-empresa-publica. Acesso em: 11 abr. 2018.

BEZERRA, Gleicy Jardi; SCHLINDWEIN, Madalena Maria. Agricultura Familiar como Geração de Renda e Desenvolvimento Local: uma Análise para Dourados, MS, Brasil. Interações Revista Internacional de Desenvolvimento Local, Campo Grande, v. 18, jan./mar. 2017, p. 315. Disponível em: http://www.scielo.br/pdf/inter/v18n1/1518-7012-inter-18-01-0003.pdf. Acesso em: 21 abr. 2019.

BRASIL. Lei no 5.851, de 7 de Dezembro de 1972. Disponível em: http://www.planalto.gov.br/ ccivil_03/leis/1970-1979/L5851.htm. Acesso em: 01 dez. 2018.

BRASIL. Constituição da República Federativa do Brasil de 1988. Disponível em: http:// www.planalto.gov.br/ccivil 03/Constituicao/Constituicao.htm. Acesso em: 31 dez. 2018.

BRASIL. Lei no 11.326, de 24 de Julho de 2006. Disponível em: http://www.planalto.gov.br/ ccivil 03/Ato2004-2006/2006/Lei/L11326.htm. Acesso em: 02 dez. 2018.

BRASIL. Decreto no 6.040, de 7 de Fevereiro de 2007. Disponível em: http://www.planalto.gov.br/ccivil_03/_Ato2007-2010/2007/Decreto/D6040.htm. Acesso em: 19 abr. 2019.

BRESSER-PEREIRA, Luiz Carlos. Tendência Declinante da Taxa de Lucro e Progresso Técnico. Revista de Economia Política, v. 6, n. 4, out./dez., 1986, p. 22-49. Disponível em: http:// www.rep.org.br/pdf/24-2.pdf. Acesso em: 30 mar. 2019.

CABRAL, Mário André Machado. Subdesenvolvimento e Estado de Exceção: O Papel da Constituição Econômica e do Estado no Brasil. Rio de Janeiro: Lumen Juris, 2018.

CABRAL, Mário André Machado; MASCARENHAS, Fábio Sampaio. Meio Ambiente, Constituição e Direito Econômico: Argumentos Econômicos versus Proteção Animal. Revista Brasileira de Direito Animal, Salvador, v. 13, n. 03, set./dez. 2018, p. 77-89. Disponível em: https:// portalseer.ufba.br/index.php/RBDA/article/download/28578/16985. Acesso em: 28 abr. 2019.

CALEGARE, Marcelo Gustavo Aguilar; HIGUCHI, Maria Inês Gasparetto; BRUNO, Ana Carla dos Santos. Povos e Comunidades Tradicionais: das Áreas Protegidas à Visibilidade Política de Grupos Sociais Portadores de Identidade Étnica e Coletiva. Ambiente \& Sociedade. São Paulo, v. XVII, n. 3, jul./set. 2014, p. 115-134. Disponível em: http://www.scielo.br/pdf/asoc/ v17n3/v17n3a08.pdf. Acesso em: 19 abr. 2019. 
CANAVESI, Flaviane de Carvalho; BIANCHINI, Valter; SILVA, Hur Ben Corrêa da. Inovação na Agricultura Familiar no Contexto da Extensão Rural e da Transição Agroecológica. Disponível em: http://www.ipea.gov.br/portal/images/stories/PDFs/livros/livros/144174_politica_nacional_agroecologia_cap13.pdf. Acesso em: 27 fev. 2019, p. 383-401.

COMPARATO, Fábio Konder. O Indispensável Direito Econômico. In: COMPARATO, Fábio Konder. Ensaios e Pareceres de Direito Empresarial. Rio de Janeiro: Forense, 1978, p. 453472.

COUTINHO, Luciano. O Redesenho da Economia Mundial. Valor Econômico, 07 de jun. 2018. Disponível em: https://www.valor.com.br/opiniao/5576323/o-redesenho-da-economia-mundial. Acesso em: 07 jun. 2018.

CONTROLADORIA-GERAL DA UNIÃO. Portal da Transparência. Empresa Brasileira de Pesquisa Agropecuária - EMBRAPA. Despesas do órgão: Execução Orçamentária e Financeira. Disponível em: http://www.portaltransparencia.gov.br/orgaos/22202?ano=2019. Acesso em: 19 abr. 2019.

CRESPI, Tatiane Baseggio; COSTA, Priscila Resende da; PORTO, Geciane Silveira; PREUSLER, Taísa Scariot. EMBRAPA: Estrutura Organizacional e Gestão de P\&D. In: VI Simpósio Internacional de Gestão de Projetos, Inovação e Sustentabilidade, São Paulo: SINGEP, 2017. Disponível em: https://singep.org.br/6singep/resultado/454.pdf. Acesso em: 11 fev. 2019.

EMPRESA BRASILEIRA DE PESQUISA AGROPECUÁRIA. Agricultura Familiar: Prioridade da Embrapa. Brasília: Embrapa, 2001. Disponível em: https://www.alice.cnptia.embrapa.br/bitstream/doc/106003/1/seatexto09.pdf. Acesso em: 01 maio 2019.

EMPRESA BRASILEIRA DE PESQUISA AGROPECUÁRIA. Embrapa em Números. 2017. Disponível em: https://www.embrapa.br/embrapa-em-numeros. Acesso em: $01 \mathrm{dez} .2018$.

EMPRESA BRASILEIRA DE PESQUISA AGROPECUÁRIA. Novos Projetos Vão Priorizar a Inovação. Embrapa, 16 de abr. 2018. Disponível em: https://www.embrapa.br/en/busca-de-noticias/-/noticia/33422090/novos-projetos-vao-priorizar-a-inovacao. Acesso em: 01 abr. 2019.

FALEIRO, Fábio Gelape; FARIAS NETO, Austeclinio Lopes de; RIBEIRO JÚNIOR, Walter Quadros. Pré-Melhoramento, Melhoramento e Pós-Melhoramento: estratégias e desafios. Disponível em: http://ainfo.cnptia.embrapa.br/digital/bitstream/CPAC-2010/29835/1/faleiro02.pdf. Acesso em: 25 fev. 2019.

FURTADO, Celso. Brasil: a construção interrompida. 2. ed. Rio de Janeiro: Paz e Terra, 1992.

FURTADO, Celso. Teoria e Política do Desenvolvimento Econômico. 10. ed. São Paulo: Paz e Terra, 2000.

FURTADO, Celso. Criatividade e Dependência na Civilização Industrial. São Paulo: Companhia das Letras, 2008.

GOEDERT, Wenceslau; CASTRO, Antônio Maria Gomes de; PAEZ, Maria Lúcia D’Ápice. O Sistema Embrapa de Planejamento. In: Revista de Administração, São Paulo, v. 30, n. 4, p. 1933, out./dez., 1995. Disponível em: http://rausp.usp.br/wp-content/uploads/files/3004019.pdf. Acesso em: 02 maio 2019.

GUIMARÃES, Elian. Agricultura Familiar Já Responde por Metade da Produção de Alimentos do País. Jornal do Estado de Minas, Belo Horizonte, 07 maio 2018. Disponível em: https:// 
Inovação e desenvolvimento agrário: o macroprograma de agricultura familiar da Embrapa e os objetivos constitucionais

www.em.com.br/app/noticia/agropecuario/2018/05/07/interna agropecuario,956711/agricultura-familiar-metade-da-producao-de-alimentos-mesa-brasileiros.shtml. Acesso em: 30 mar. 2019.

GRAU, Eros Roberto. O Direito Posto e o Direito Pressuposto. 7. ed. São Paulo: Malheiros, 2008, p. 59 e $126-127$

GUANZIROLI, Carlos Enrique; CARDIM, Silvia Elisabeth (Coord.). Novo Retrato da Agricultura Familiar: O Brasil Redescoberto. Brasília: 2000. Disponível em: https://www.agencia.cnptia.embrapa.br/recursos/novoretratoID-3iTs4E7R59.pdf. Acesso em: 25 fev. 2019.

GUANZIROLI, Carlos Enrique; BUAINAIN, Antonio Marcio; SABBATO, Alberto Di. Dez Anos de Evolução da Agricultura Familiar no Brasil: (1996 e 2006). RESR, Piracicaba, v. 50, n. 2, 2012, p. 351-370. Disponível em: http://www.scielo.br/pdf/resr/v50n2/v50n2a09. Acesso em: 25 fev. 2019.

HOFFMANN, Rodolfo. A Agricultura Familiar Produz 70\% dos Alimentos Consumidos no Brasil?. Segurança Alimentar e Nutricional, Campinas, v. 21, n. 1, 2014, p. 417-421. Disponível em: http://coral.ufsm.br/ppgagr/images/Documentos/AF70.pdf. Acesso em: 30 mar. 2019.

INSTITUTO BRASILEIRO DE GEOGRAFIA E ESTATÍSTICA. Censo Agropecuário de 2006. Disponível em: http://www.mma.gov.br/estruturas/PZEE/_arquivos/censo_agropecurio_ 2006 28.pdf. Acesso em: 30 mar. 2019.

INSTITUTO BRASILEIRO DE GEOGRAFIA E ESTATÍSTICA. Censo Agropecuário de 2017. Disponível em: https://censos.ibge.gov.br/agro/2017. Acesso em: 30 mar. 2019.

JUNIOR, Chico. A Hora e a Vez da Agricultura Familiar. O Globo, Rio de Janeiro, 08 de jan. 2018. Disponível em: https://oglobo.globo.com/opiniao/a-hora-a-vez-da-agricultura-familiar22259699. Acesso em: 26 mar. 2019.

MENDES, Luis Augusto Lobão; ONO, Mauri Seiji (Orgs.). Conselho Estratégico: Guia da Alta Administração para o Desenvolvimento da Estratégia Corporativa. São Paulo: Saraiva, 2014.

OCTAVIANI, Alessandro. Recursos Genéticos e Desenvolvimento: Os Desafios Furtadiano e Gramsciano. São Paulo: Saraiva, 2013.

OCTAVIANI, Alessandro. Estudos, Pareceres e Votos de Direito Econômico. São Paulo: Singular, 2014.

OCTAVIANI, Alessandro; NOHARA, Irene. Estatais. São Paulo: Thomson Reuters Brasil, 2019.

PENTEADO, Maria Isabel de Oliveira; FONTES, Ruy Rezende; CAMPOS, Antônio de Araújo; EUCLIDES FILHO, Kepler. A Trajetória do Planejamento de Pesquisa na Embrapa. In: Cadernos de Ciência \& Tecnologia, Brasília, v. 31, n. 1, jan./abr., 2014, p. 35-60. Disponível em: https://www.alice.cnptia.embrapa.br/alice/bitstream/doc/986015/1/Trajetoriadoplanejamentodapesquisa.pdf. Acesso em: 05 jan. 2019.

PEIXOTO, Marcos. Extensão Rural no Brasil - Uma Abordagem Histórica da Legislação. Consultoria Legislativa do Senado Federal, Textos Para Discussão, n. 48, Brasília, 2008. Disponível em: https://www12.senado.leg.br/publicacoes/estudos-legislativos/tipos-de-estudos/textos-para-discussao/td-48-extensao-rural-no-brasil-uma-abordagem-historica-da-legislacao.

Acesso em: 19 abr. 2019.

RAMOS, Pedro; PIACENTE; Fabrício José. O Instituto Agronômico de Campinas: Sua Criação, Importância e um Pouco de sua História. Revista Brasileira de Inovação, n. 15, jul./dez., 2016, 
p. 365-392. Disponível em: https://periodicos.sbu.unicamp.br/ojs/index.php/rbi/article/view/ 8649134/15683. Acesso em: 19 abr. 2019.

REICH, Norbert. Markt und Recht: Theorie und Praxis des Wirtschaftsrecht in der Bundesrepublik Deutschland. Neuwied/Darmstadt: Hermann Luchterhand, 1977, p. 64-66.

SALGADO, Rodrigo Oliveira. Constituição e Desenvolvimento: o mercado interno na Constituição de 1988. Dissertação (Mestrado em Direito Econômico e Financeiro) - Faculdade de Direito da Universidade de São Paulo, São Paulo, 2013.

SCHMITZ, Heribert; MOTA, Dalva Maria da. Agricultura Familiar: elementos teóricos e empíricos. Agrotópica, Ilhéus, v. 19, jan./dez., 2007, p. 21-30. Disponível em: http://www.ceplac.gov.br/paginas/agrotropica/revistas/agrotropica_19 1.pdf\#page=24. Acesso em: $02 \mathrm{maio}$ 2019.

SOCIEDADE NACIONAL DE AGRICULTURA. Embrapa Anuncia Plano de Demissão Voluntária. Disponível em: https://www.sna.agr.br/embrapa-anuncia-plano-de-demissao-voluntaria/. Acesso em: 09 mar. 2019.

WIENKE, Felipe Franz. A Noção de Agricultura Familiar no Direito Brasileiro: Uma Conceituação em Torno de Elementos Socioeconômicos e Culturais. JURIS, Rio Grande, v. 27, n. 1, p. 225-245. Disponível em: https://periodicos.furg.br/juris/article/viewFile/6966/4611. Acesso em: 26 fev. 2019.

ZENERATTI, Fábio Luiz. Propriedade e Latifúndio: Introdução ao Debate sobre sua Origem e Perpetuação no Brasil. Caderno de Geografia, v. 27, n. 50, 2017, p. 441-454. Disponível em: http://periodicos.pucminas.br/index.php/geografia/article/download/p.23182962.2017v27n50p441/11756. Acesso em: 02 maio 2019.

Recebido em: 27 abr. 2020.

Aceito em: 6 dez. 2020. 